\title{
Primary care for opioid use disorder
}

This article was published in the following Dove Press journal:

Substance Abuse and Rehabilitation

16 August 2016

Number of times this article has been viewed

\section{Paolo Mannelli' \\ Li-Tzy Wu ${ }^{1-4}$}

'Department of Psychiatry and Behavioral Sciences, ${ }^{2}$ Department of Medicine, ${ }^{3}$ Duke Clinical Research Institute, Duke University Medical Center, ${ }^{4}$ Center for Child and Family Policy, Sanford School of Public Policy, Duke University, Durham, NC, USA

Correspondence: Paolo Mannelli

Duke University Medical Center, 2213

Elba Street, Suite 156, DUMC 3074,

Durham, NC 27705, USA

Tel + I 9196683757

Fax +1 9196685418

Email paolo.mannelli@duke.edu

Li-Tzy Wu

Department of Psychiatry and Behavioral Sciences, Psychiatry Box 3903, Duke University Medical Center, Durham, NC 277I0, USA

Email litzy.wu@duke.edu
Recent reports on prescription opioid misuse and abuse have described unprecedented peaks of a national crisis and the only answer is to expand prevention and treatment, including different levels of care. ${ }^{1}$ Nonetheless, concerns remain about the ability of busy primary care settings to manage problem opioid users along with other patients. In particular, proposed extensions of buprenorphine treatment, a critically effective intervention for opioid use disorder (OUD), are cautiously considered due to the potential risk of misuse or abuse. ${ }^{2}$ General practitioners are already facing this burden daily in the treatment of chronic pain, and expert supervision and treatment model adjustment are needed to help improve outcomes. Approximately $20 \%$ of patients in primary care have noncancer pain symptoms, with most of them receiving opioid prescriptions by their physicians, and their number is increasing. ${ }^{3}$ Pain diagnoses are comparable in severity to those of tertiary centers and are complicated by significant psychiatric comorbidity, with a measurable lifetime risk of developing OUD. ${ }^{4,5}$ Some primary care physicians report frustration about opioid abuse and diversion by their patients; support from pain specialists would improve their competence, the quality of their performance, and the ability to identify patients at risk of opioid misuse. ${ }^{6}$ Thus, buprenorphine treatment should not be adding to a complex clinical scenario. To this end, the promising models of care emphasize the integration of medical with psychological and pharmacological expertise for the management of OUD.

Primary care is an important entry point for all patients suffering from chronic conditions, including substance use disorders. Even in the absence of chronic opioid therapy for pain as a predictor of problem opioid use, the wealth of medical and behavioral information available for a diagnosis is potentially unmatched by what the tertiary level physician (or specialist) would be able to gather. Despite limited time and the self-reported low level of preparedness, primary care is arguably the ideal place where substance use treatment can be successfully integrated into medical care, if adequate support is guaranteed. In addition to psychosocial, educational, and integrated treatments for substance use disorders, office-based buprenorphine therapy has demonstrated adaptability to a primary care setting. ${ }^{7}$ Also, buprenorphine primary care prescribers have gradually been closing the number gap with psychiatrists, though a reduced presence in rural areas and a low prescribing rate continue to leave part of the demand unanswered, ${ }^{8,9}$ indicating the work to be done even before buprenorphine treatment expansion occurs. In some areas of the US, there are less than three prescribers 
per 100,000 persons, the average number of patients for certified prescribers is only one-quarter of the current limit of 100 , and one-quarter of physicians with a waiver have never prescribed the medication. ${ }^{2}$

Of course, the setting is instrumental and the standard quality of care is importantly correlated with composite outcomes. In Federally Qualified Health Centers, which provide patient-centered health care services and systematic focus on quality as defined in the Affordable Care Act, the implementation of buprenorphine treatment has been associated with improved medical outcome and health indicators, as well as with longer retention compared to specialist treatment. ${ }^{10}$ Thus, supervision and mentoring by tertiary level specialists may enhance the knowledge and self-confidence of prescribers to boost the rate of prescriptions, while telemedicine web-based interventions and the use of long-acting medication formulations could assist the attempt to delve into underserved area. ${ }^{11,12}$ However, for better results, the clinical environment must be patient-centered, and substance use disorder management has to receive as much attention as other problems, producing a synergistic effect to improve the quality of life of patients.

Effective responses to minimize physician burden, optimize care, and prevent diversion can be primarily identified in the extension of collaborative care involving the physician assistants, nurse practitioners, and pharmacists more directly in the prescription or dosing of buprenorphine. The dissemination of this type of interventions has gone through years of experimental application and is now being extended to clinical practice. ${ }^{13,14}$ Additional instruments to monitor and prevent buprenorphine diversion and abuse are already available in many cases of evidence-based standard of care. Treatment teams can routinely share medical information through electronic health records, and the prescription of redflagged medications can be monitored as potentially harmful, in full respect of protected health information. ${ }^{15}$ Currently, 49 states and the District of Columbia have authorized the creation of prescription drug monitoring programs, and pain specialists as well as buprenorphine prescribers who may want to expand treatment numbers following a legislative act are recommended by policies and guidelines to more closely review the records of their patients for doctor shopping and multiple prescriptions of controlled substances to treat the same symptoms. ${ }^{16}$

Nonetheless, the more effective abuse prevention and intervention tools consist of providing valid treatment alternatives. From a pharmacological standpoint, naloxone prescribing for overdose prevention complements the basic educational strategies that can be employed in primary care, giving physicians the opportunity to prevent mortality even among patients who have not formally entered addiction treatment "status". Recently introduced long-acting buprenorphine formulations open up the possibility of reducing treatment costs and maximizing the use of primary care by decreasing the frequency of prescriber visits. ${ }^{17}$ The option of using slow-release naltrexone also adds to this outlook the potentiality of an opioid antagonist treatment to prevent relapse without abuse potential or the need to manage opioid withdrawal symptoms at discontinuation. Naltrexone is not classified as a controlled substance and can be prescribed in primary care settings by physicians, physician assistants, or nurse practitioners, but the clinical use has been limited by low patient acceptance and difficult transition from opioid agonist therapies. ${ }^{18}$ Further research on these and other medications and their combination with behavioral interventions in primary care settings will be instrumental for informing future efforts at dissemination and expansion of OUD treatment while understanding the optimal methods for coordination and integration of care. Other future research venues include, but are not limited to, the recognition of patient improvement in relation to specific types and intensity of psychosocial services, and the identification of indicators of quality of care and their measurement. Given the high comorbidity levels in this population, research on management of OUD with psychiatric comorbidity, use of multiple substances, and/or medical complications is also important to inform and reinforce evidence-based approaches.

Treatment of substance use disorders is an essential health benefit under the health care reform. Increasing numbers of individuals with OUD are acquiring health insurance, which should facilitate their access to evidencebased treatments for OUD. The answer cannot be to push them into the bottleneck of specialty care, not before a long waiting time and the risk of patients to be lost in the gap between primary care and specialty treatment. The goal is to offer patient-centered treatment for OUD, including shared decision making about medications and evidence-based interventions, and the primary care environment perhaps looks like the best one to reach it.

\section{Acknowledgments}

Paolo Mannelli and Li-Tzy Wu have received research support from the US National Institutes of Health (UG1DA040317, R01MD007658, and R01DA019623). The sponsoring agency had no further role in the writing of the report or the decision to submit the paper for publication. The opinions expressed in this paper are solely those of the authors. 


\section{Disclosure}

Paolo Mannelli has received research funding from Orexo and Alkermes Inc and has served on a Scientific Advisory Board for Alkermes Inc. The authors have no other conflicts of interest to disclose.

\section{References}

1. Kanouse AB, Compton P. The epidemic of prescription opioid abuse, the subsequent rising prevalence of heroin use, and the federal response. J Pain Palliat Care Pharmacother. 2015;29(2):102-114.

2. Li X, Shorter D, Kosten TR. Buprenorphine prescribing: to expand or not to expand. J Psychiatr Pract. 2016;22(3):183-192.

3. Dowell D, Haegerich TM, Chou R. CDC guideline for prescribing opioids for chronic pain — United States, 2016. MMWR Recomm Rep. 2016;65(1):1-49.

4. Fink-Miller EL, Long DM, Gross RT. Comparing chronic pain treatment seekers in primary care versus tertiary care settings. J Am Board Fam Med. 2014;27(5):594-601.

5. Weiss RD, Potter JS, Griffin ML, et al. Reasons for opioid use among patients with dependence on prescription opioids: the role of chronic pain. J Subst Abuse Treat. 2014;47(2):140-145.

6. Jamison RN, Scanlan E, Matthews ML, Jurcik DC, Ross EL. Attitudes of primary care practitioners in managing chronic pain patients prescribed opioids for pain: a prospective longitudinal controlled trial. Pain Med. 2016;17(1):99-113.

7. Komaromy M, Duhigg D, Metcalf A, et al. Project ECHO (Extension for Community Healthcare Outcomes): a new model for educating primary care providers about treatment of substance use disorders. Subst Abus. 2016;37(1):20-24

8. Hutchinson E, Catlin M, Andrilla CH, Baldwin LM, Rosenblatt RA. Barriers to primary care physicians prescribing buprenorphine. Ann Fam Med. 2014;12(2):128-133.
9. Rosenblatt RA, Andrilla CH, Catlin M, Larson EH. Geographic and specialty distribution of US physicians trained to treat opioid use disorder. The Annals of Family Medicine. 2015;13(1):23-26.

10. Haddad MS, Zelenev A, Altice FL. Buprenorphine maintenance treatment retention improves nationally recommended preventive primary care screenings when integrated into urban federally qualified health centers. J Urban Health. 2015;92(1):193-213.

11. Providers' Clinical Support System for Medication Assisted Treatment [PCSSMAT]. Available from: http://pcssmat.org/. Accessed May 30, 2016.

12. Marsch LA, Guarino H, Acosta M, et al. Web-based behavioral treatment for substance use disorders as a partial replacement of standard methadone maintenance treatment. J Subst Abuse Treat. 2014;46(1):43-51.

13. LaBelle CT, Han SC, Bergeron A, Samet JH. Office-based opioid treatment with buprenorphine (OBOT-B): statewide implementation of the Massachusetts Collaborative Care Model in Community Health Centers. J Subst Abuse Treat. 2016;60:6-13.

14. Weiss L, Egan JE, Botsko M, Netherland J, Fiellin DA, Finkelstein R. The BHIVES collaborative: organization and evaluation of a multisite demonstration of integrated buprenorphine/naloxone and HIV treatment. J Acquir Immune Defic Syndr. 2011;56 (Suppl 1):S7-S13.

15. Tanner C, Gans D, White J, Nath R, Pohl J. Electronic health records and patient safety: co-occurrence of early EHR implementation with patient safety practices in primary care settings. Appl Clin Inform. 2015; $6(1): 136-147$

16. Brady JE, Wunsch H, DiMaggio C, Lang BH, Giglio J, Li G. Prescription drug monitoring and dispensing of prescription opioids. Public Health Rep. 2014;129(2):139-147.

17. U.S. Food and Drug Administration (FDA), 2016. FDA approves first buprenorphine implant for treatment of opioid dependence. http://www. fda.gov/NewsEvents/Newsroom/PressAnnouncements/ucm503719. htm. Accessed on July 17, 2016.

18. Mannelli P, Peindl KS, Wu LT. Pharmacological enhancement of naltrexone treatment for opioid dependence: a review. Subst Abuse Rehabil. 2011;2011(2):113-123

Dove Medical Press encourages responsible, free and frank academic debate. The content of the Substance Abuse and Rehabilitation 'Editorial' section does not necessarily represent the views of Dove Medical Press, its officers, agents, employees, related entities or the Substance Abuse and Rehabilitation editors. While all reasonable steps have been taken to confirm the content of each Editorial, Dove Medical Press accepts no liability in respect of the content of any Editorial, nor is it responsible for the content and accuracy of any Editorial.

\section{Publish your work in this journal}

Substance Abuse and Rehabilitation is an international, peer-reviewed, open access journal publishing original research, case reports, editorials, reviews and commentaries on all areas of addiction and substance abuse and options for treatment and rehabilitation. The manuscript management system is completely online and includes a very quick and fair

\section{Dovepress}

peer-review system. Visit http://www.dovepress.com/testimonials.php to read real quotes from published authors. 